\title{
Effects of Two Exercise Modalities of Sprint Interval Training and Combined Training (Strength-Aerobic) on Serum Apelin Levels and Insulin Resistance in Females with Type 2 Diabetes
}

\author{
Samira Nasiri ${ }^{1}$, Ebrahim Banitalebi ${ }^{1, *}$, Mohammad Faramarzi ${ }^{1}$ \\ ${ }^{1}$ Department of Sport Sciences, Shahrekord University, Shahrekord, Iran \\ * Corresponding author: Ebrahim Banitalebi, Department of Sport Sciences, Shahrekord University, \\ Shahrekord, Iran. E-mail: banitalebi@ lit.sku.ac.ir
}

Received: 01 Oct 2016

Accepted: 06 Sep 2017

\begin{abstract}
Introduction: Exercise activity is an effective treatment tool for the management of patients with type 2 diabetes. The purpose of this study was to investigate the effects of 8 weeks of combined and Sprint Interval Training (SIT) on serum apelin levels and insulin resistance in females with type 2 diabetes.
\end{abstract}

Methods: Fifty-two overweight females with type 2 diabetes (aged 45 to 60 years old, BMI > 30) with $\mathrm{HbA1C}$ value of $6.5 \%$ were assessed for eligibility. Participants were assigned to the SIT group $(n=17)$, combined training group $(n=17)$, and control group $(n=18)$, according to HbA1c levels. The exercises included 12 weeks of combined training and SIT. To determine the differences between groups, a statistical analysis of covariance and a meaningful LSD test were used to determine the difference between the groups.

Results: Difference was significant for fasting blood glucose in the SIT groups $(\mathrm{P}<0.001)$. Serum insulin levels showed significant increases in the SIT $(\mathrm{P}<0.001)$ and Com $(\mathrm{P}=0.001)$. Changes in apelin were not significantly different within SIT and combined training groups $(\mathrm{P}=0.13$ and $\mathrm{P}=$ 0.09 , respectively). The data showed significant differences in insulin resistance index (HOMA-IR) in SIT $(\mathrm{P}<0.001)$ and Com $(\mathrm{P}=0.008)$. Furthermore, the ANCOVA test showed that there were no significant differences in fasting blood glucose concentrations $(\mathrm{F}=1.853, \mathrm{P}=0.171)$ regarding apelin $(\mathrm{F}=0.511, \mathrm{P}=0.12)$ yet, significant differences were seen between groups in insulin $(\mathrm{F}=$ 3.622, $\mathrm{P}=0.036)$, and HOMA-IR $(\mathrm{F}=5.511, \mathrm{P}=0.008)$.

Conclusions: Exercise training, independent of mode of training, is an effective training method to improve glycemic control in females with type 2 diabetes.

Keywords: SIT and Combined Training, Apelin, Type 2 Diabetes 


\title{
تأثير دو شيوه تمرين تناوبى سرعتى و تركيبى (قدرتى-هوازى) بر سطوح آيلين

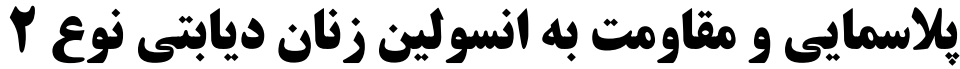

\author{
سميرا نصيرى '، ابراهيم بنىطالبى ا.*، محمد فرامرزى '
}

أكروه علوم ورزشى، دانشكاه شهركرد، شهركرد، ايران

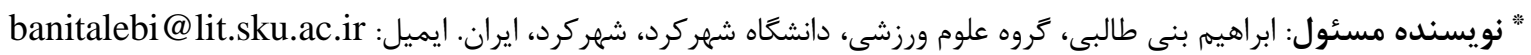

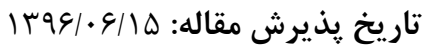

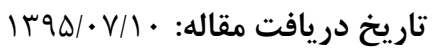

جكيده

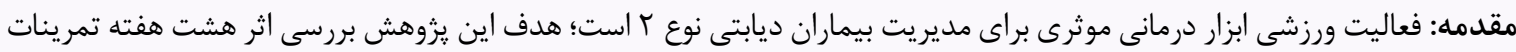

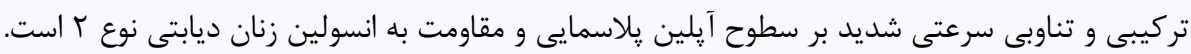

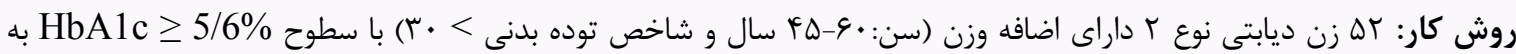

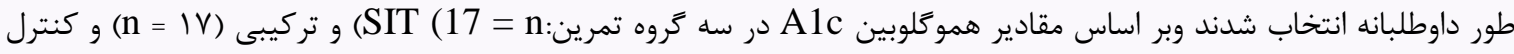

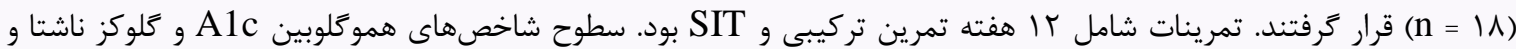

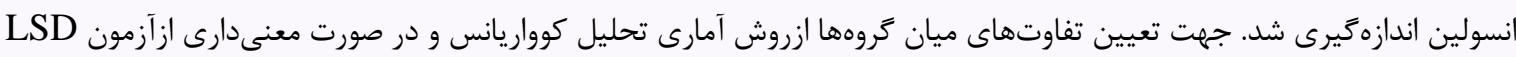

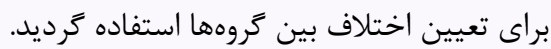

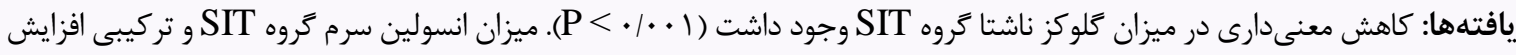

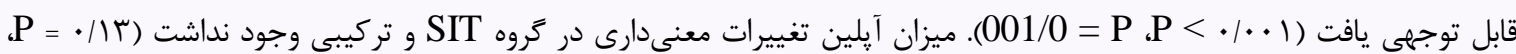

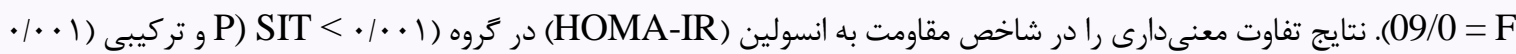

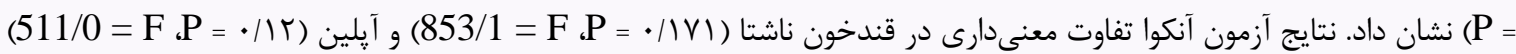

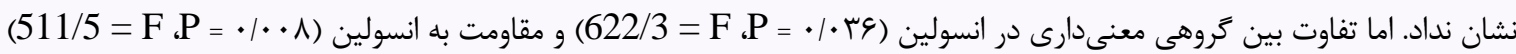
مشاهده شد. نتيجه كيرى: تمرينات ورزشى مستقل از نوع و روش انجام مى توانند اثرات مثبتى بر كنترل قندخون زنان ديابتى نوع r داشته باشند.

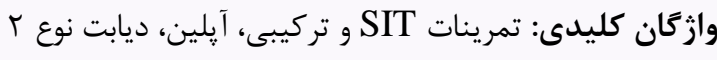

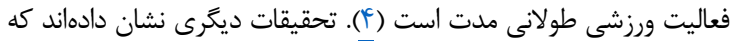

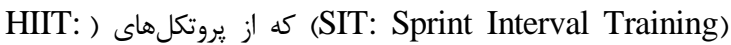
(High Intensity Interval Training

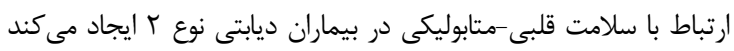

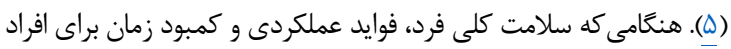

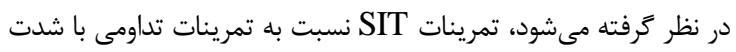

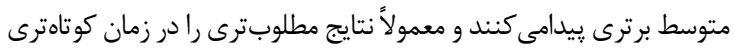

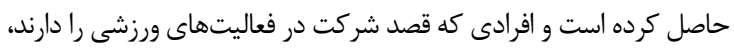

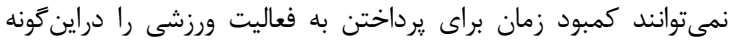

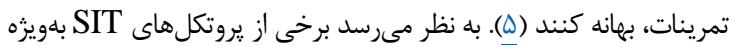

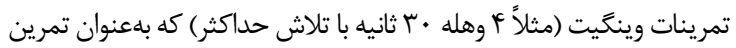

در جند دهه اخير افزايش شيوع ديابت نوع r در كشورهاى در حال توسعه،

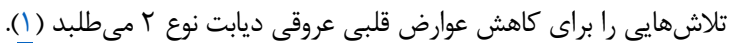

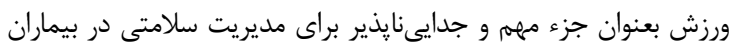

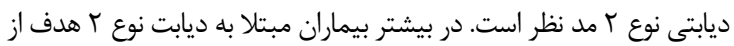

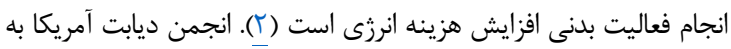

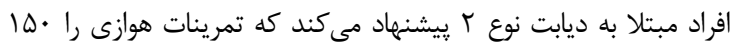

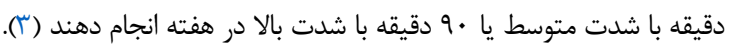

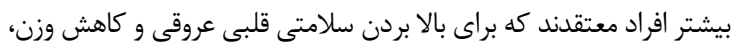

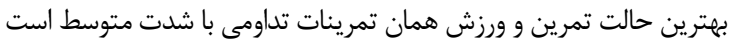

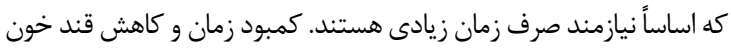

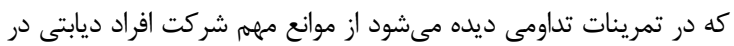


اتمام دوره تحقيق شدند و • ا نفر به علت بيمارى و عدم شركت در تمرين

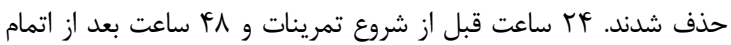

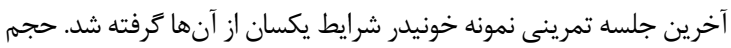

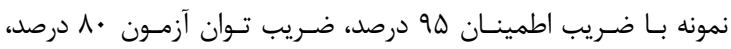

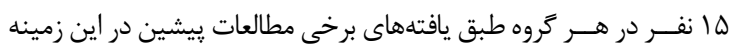

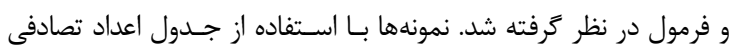

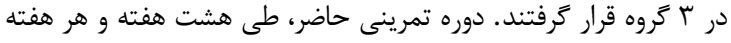

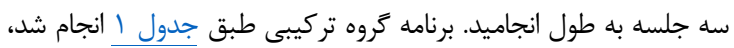

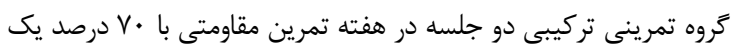

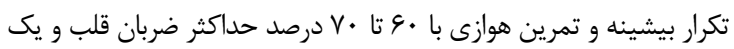
جلسه در هفته فقط تمرين هوازى انجام دادند (در مجموع سه جلسه در

هفته).

كروه تمرينى تركيبى در ابتدا برنامه تمرين قدرتى را انجام مى دادند و پِّ ديس

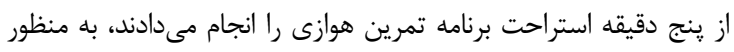

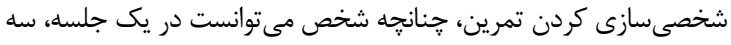

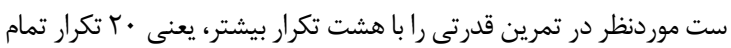

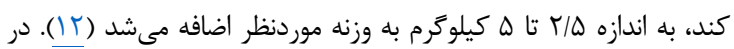

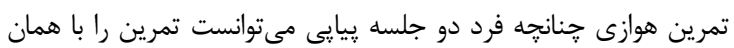

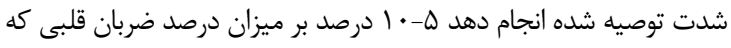

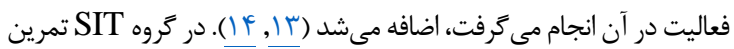

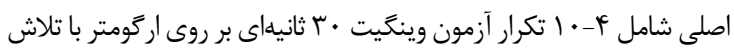

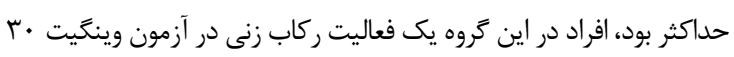

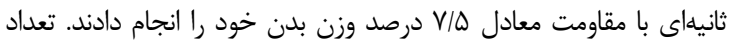

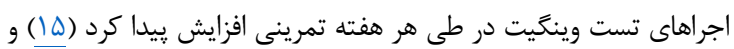

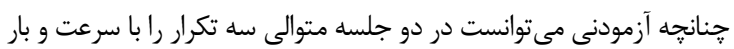

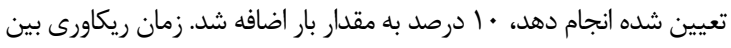

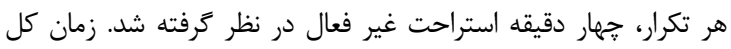

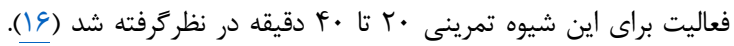

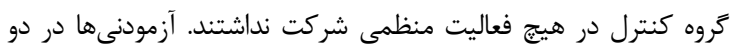

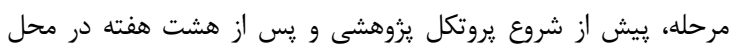

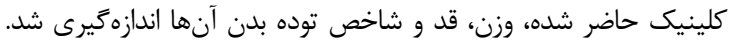

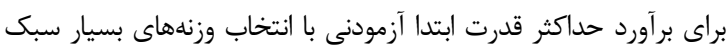

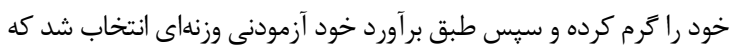

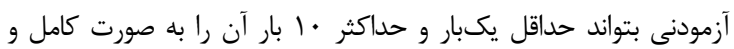

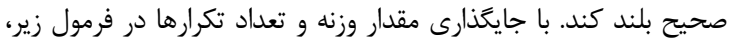

قدرت بيشينه آزمودنى در هر حركت به دست بكد آمد (IV)
سرعتى تناوبى SIT مىباشند نزديك به مداخلات تمرين مقاومتى است؛

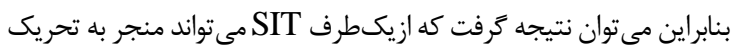

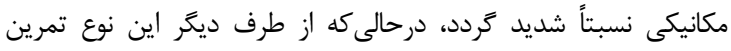

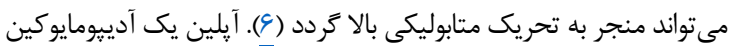

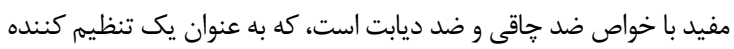

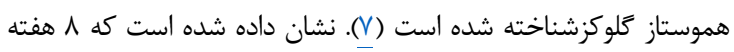

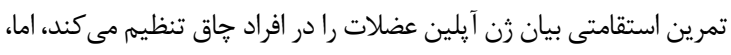

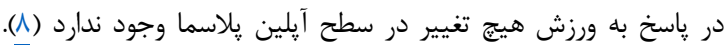

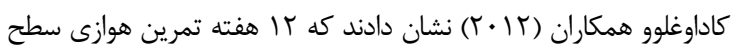

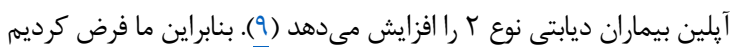

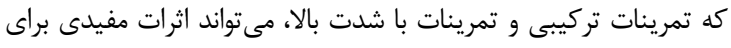

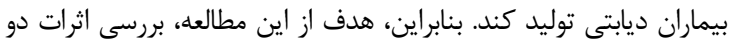

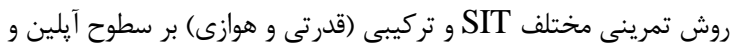

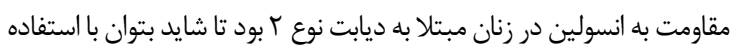

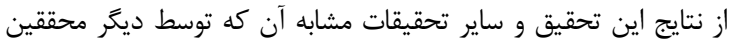

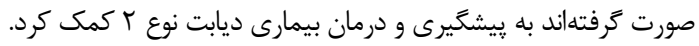

روش كار

اين تحقيق به لحاظ هدف كاربردى و به لحاظ شيوه گردآروى دادهها نيمه

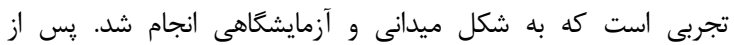

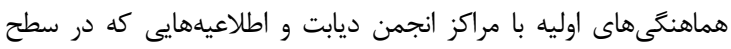

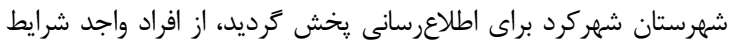

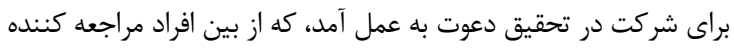

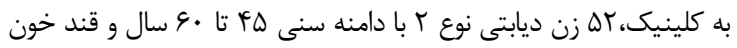

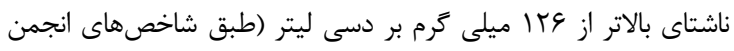

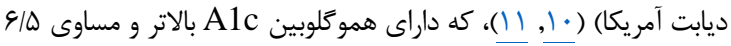

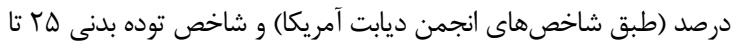

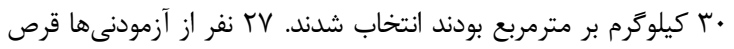

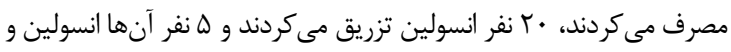

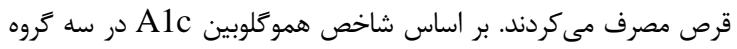

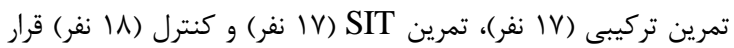

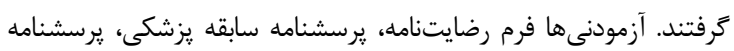

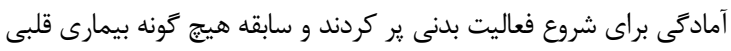

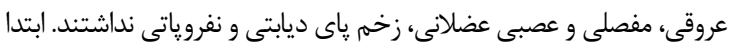

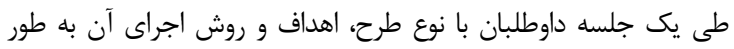

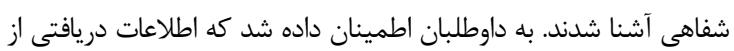

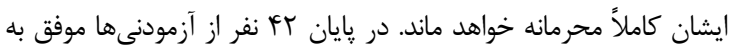

جدول ا: تمرين تركيبى (قدرتى - هوازى)

\begin{tabular}{|c|c|c|c|c|c|c|c|c|}
\hline \multicolumn{3}{|c|}{ تمرين هوازى } & \multicolumn{5}{|c|}{ تمرين قدرتى } & \multirow[t]{2}{*}{ هفته } \\
\hline تكرار (روز / هفته) & شدت (درصد & | مدت (دقيقه & تعداد جلسه & $\begin{array}{c}\text { وزن (درصد } \\
\text { (1RM }\end{array}$ & ست استراحت بين هر & 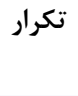 & ست & \\
\hline$r$ & 4. & 10 & $r$ & 10 & $r-r$ & 10 & 1 & آشناسازى (هفته اول) \\
\hline r & 4. & $r \cdot$ & r & 10 & $r-r$ & 10 & r & آشناسازى (هفته دوم) \\
\hline r & $v \cdot$ & ra & r & ir & $r-r$ & 10 & r & اول- دوم \\
\hline r & $v \cdot$ & $r$. & r & ir & $r-r$ & ir & r & سوم- جهارم \\
\hline r & $\vee \cdot$ & $r \cdot$ & r & IT & $r-r$ & ir & r & ينجم- ششم \\
\hline$r$ & v. & $r \cdot$ & r & 1 & $r-r$ & 1. & r & هفتم - هشتم \\
\hline
\end{tabular}




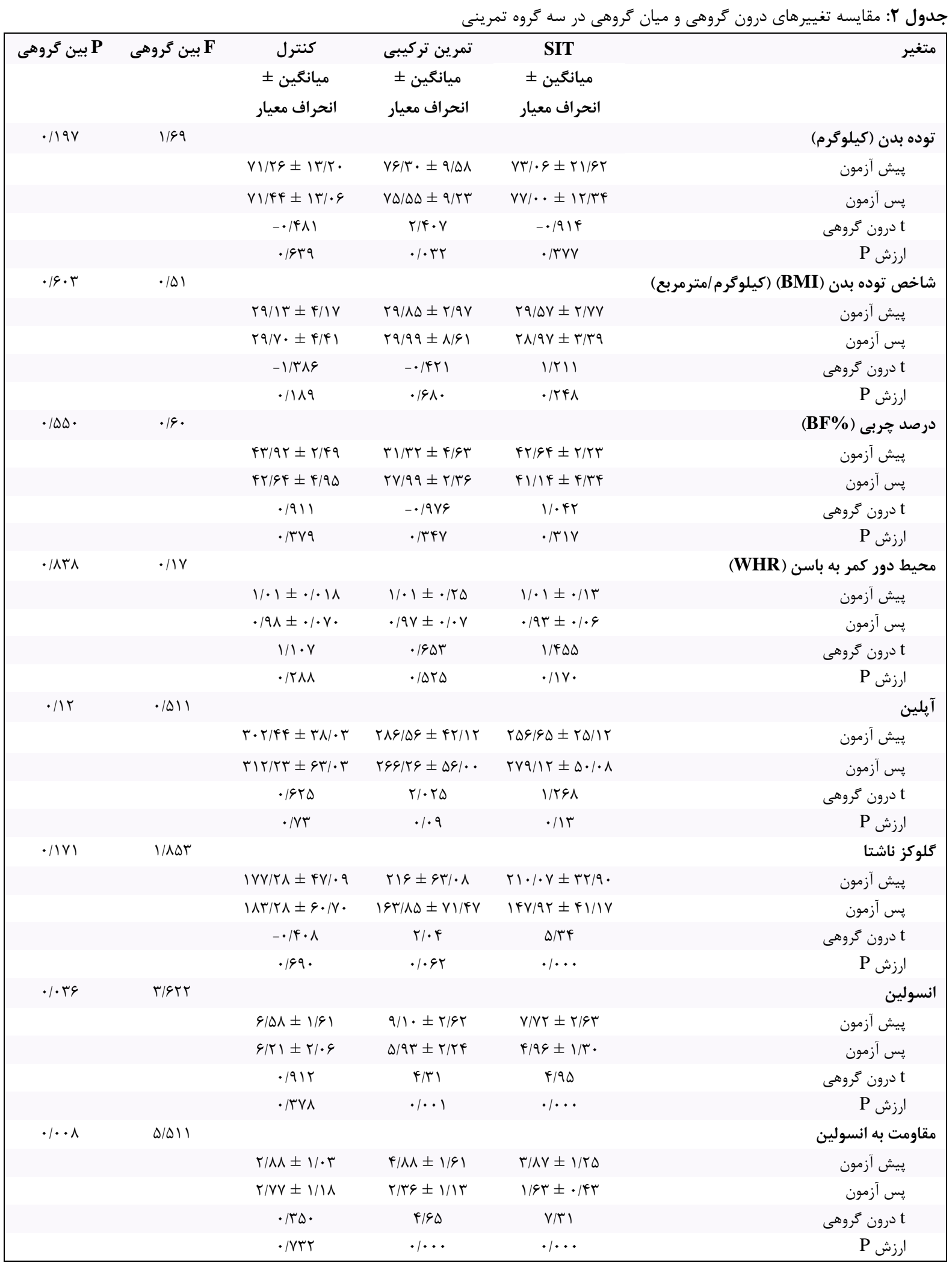

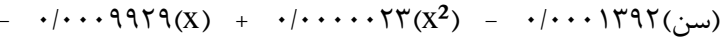

$$
\begin{aligned}
& \text { | } \\
& \text { در درصد }
\end{aligned}
$$

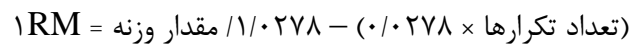

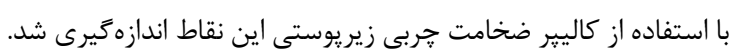

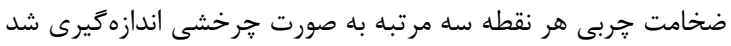

$$
\begin{aligned}
& \text { و ميانكَين آن در فرمول استفاده كرديد: }
\end{aligned}
$$


به انسولين همانند آيلين در بيماران ديابتى نوع \ وجود دارد. همانطور

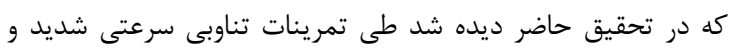

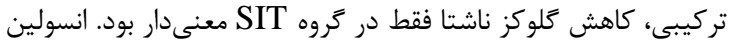

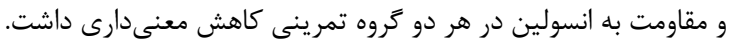

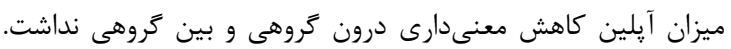

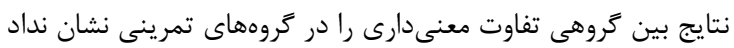

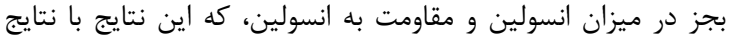

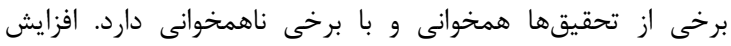

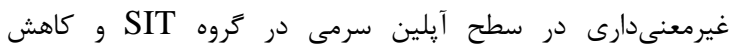

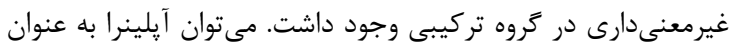
يك آدييوكين خوب درنظر كرفت .نشان داده شده است كه ده دآيلين

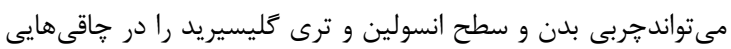

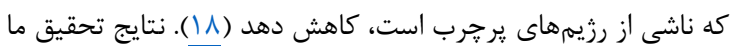

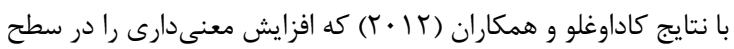

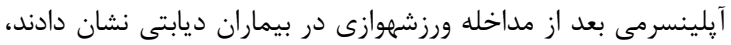

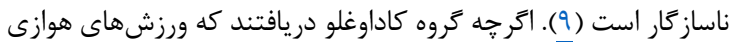

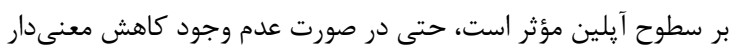

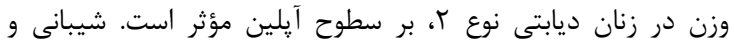

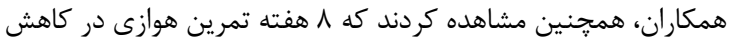

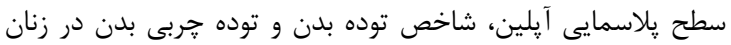

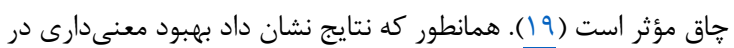

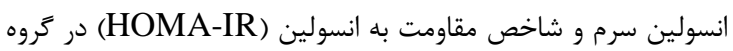
SIT

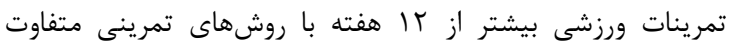
(تركيب تمرينات هوازى و مقاومت و SIT در مقايسه با ورزش بات نكردن،

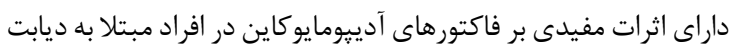

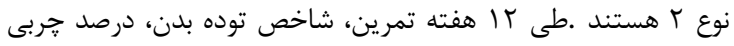

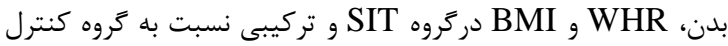
بطور معنى بار كاهش يافت .كاهش غير معنى دار مشاهده شده

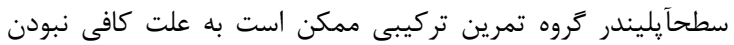

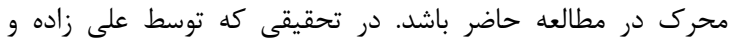

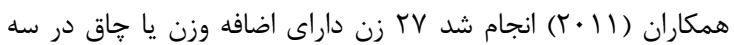

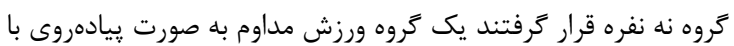

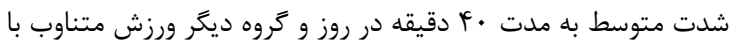

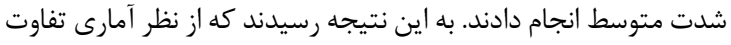

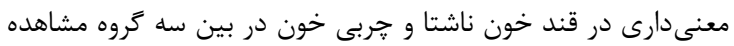

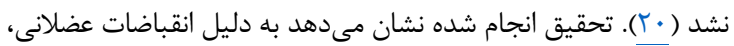

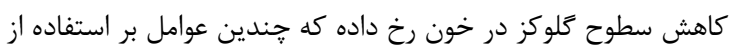

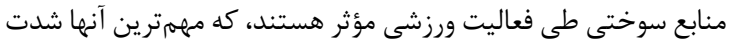

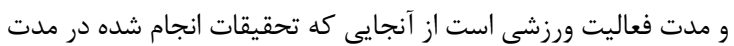

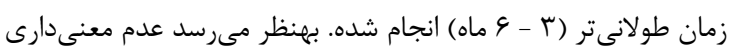

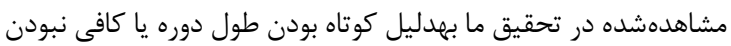
شدت تمرين باشد.

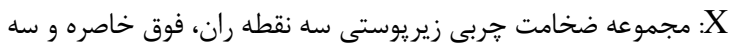

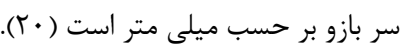

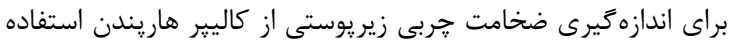

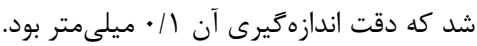

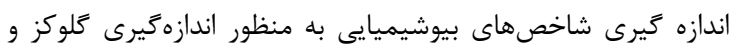

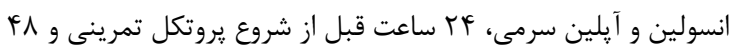

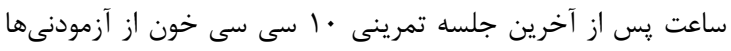
بعد از r آساعت حالت ناشتا كرفته شد.

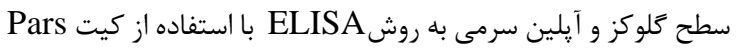
ساخت كشور ايران اندازهيرى شد. سطح انسولين سرمى به روش روش ELISA HOMA- اندازهيرى شد. براى محاسبه مقاومت به انسولين از فرمول استفاده خرديد. IR

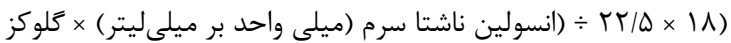

HOMA-IR = ناشتا سرم (ميلى از آمار توصيفى براى محاسبه ميانكين و انحراف معيار متغيرهاى ناى تحقيق

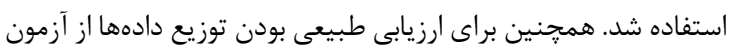

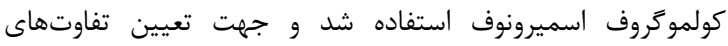
درون كروهى از آزمون t زوجى و جهت تعيين تفاوتهاى ميان گروهوفها

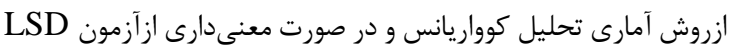

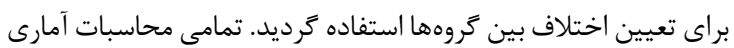

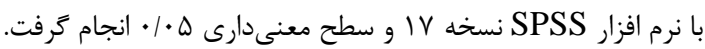

\section{يافتهها}

ويزگى هاى آنترويومتريكى، تركيب بدنى و فيزيولوزيكى و دادههاى

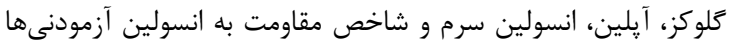

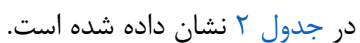

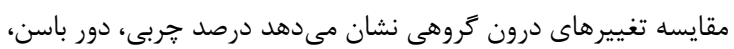

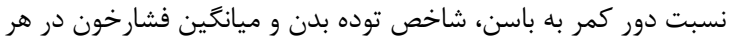

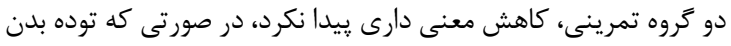

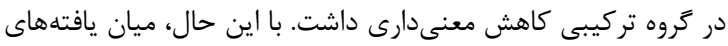

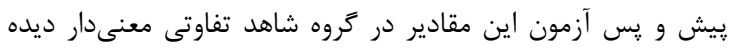

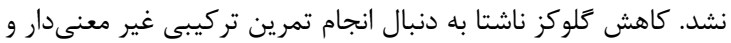

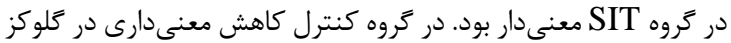

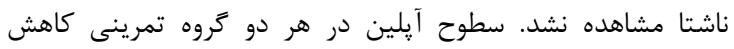

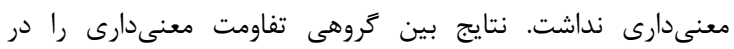

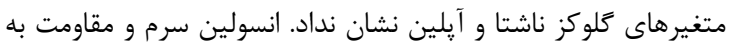

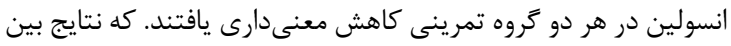

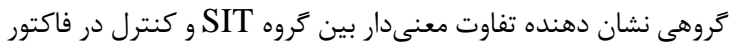

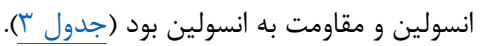

\section{بحث و نتيجه تيرى}

تنها جند مطالعه در خصوص مقايسه تأثير تمرين SIT و وتركيبى

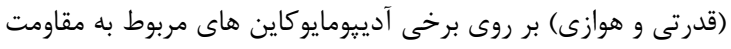




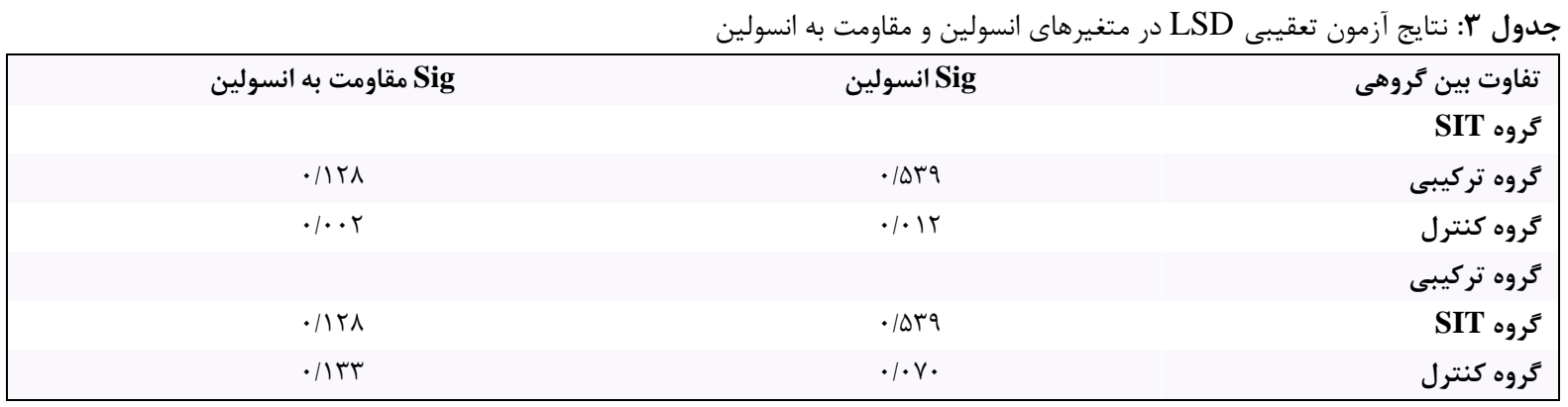

نسبت داده شده است اين درحالى است كه شاخص توده بدن در تحقيق

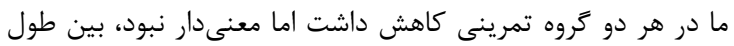

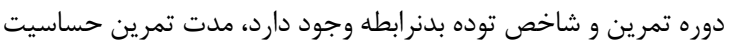

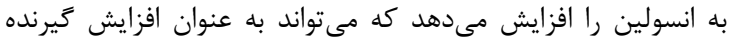

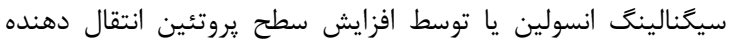

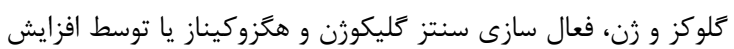

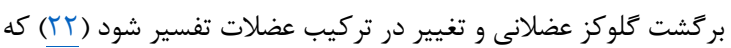

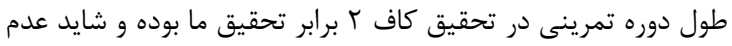

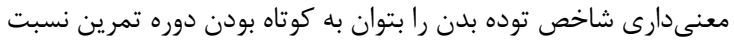

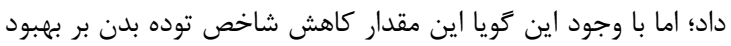

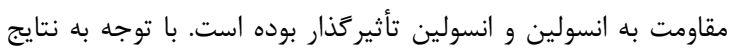

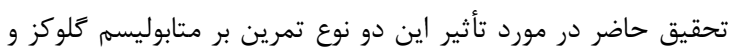

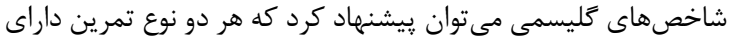

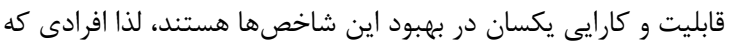

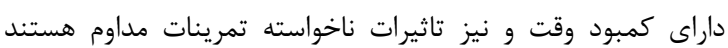

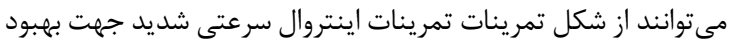

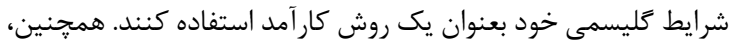

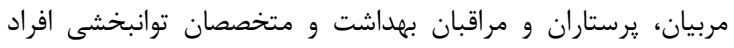

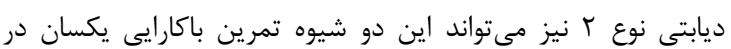
مقايسه با تمرينات تداومى توصيه نمايند.

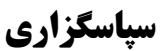

اين تحقيق با حمايت مالى معاونت يزوهشى دانشعاه شهركرد با كد اعتبار يزوهشى 95GRN1M895 انجام كرفته است

\section{References}

1. Simpson SH, Corabian P, Jacobs P, Johnson JA. The cost of major comorbidity in people with diabetes mellitus. CMAJ. 2003;168(13):1661-7. PMID: 12821619

2. Samadian Z, Tofighian A, Mehdizade A. [The effect of 12 weeks of combined training on serum resistin levels and glycemic index in obese postmenopausal women with type 2 diabetes]. Diabetes Metab J. 2013;12(6):524-33.

3. Lambers S, Van Laethem C, Van Acker K, Calders P. Influence of combined exercise training on indices of obesity, diabetes and cardiovascular risk in type 2 diabetes patients. Clin Rehabil. 2008;22(6):483-92. DOI: $10.1177 / 0269215508084582$ PMID: 18511528

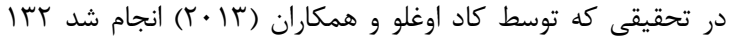

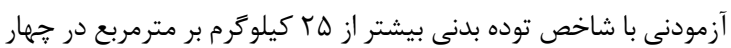

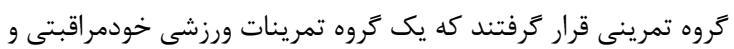

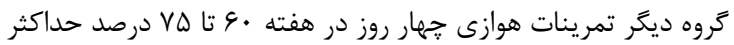

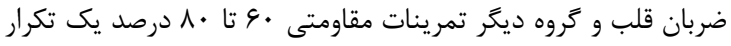

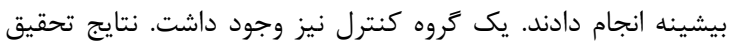

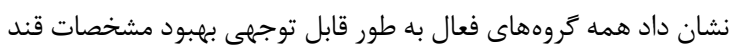

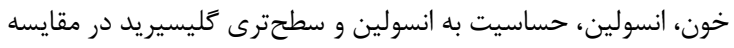

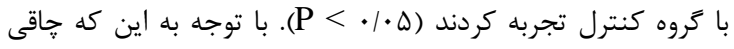

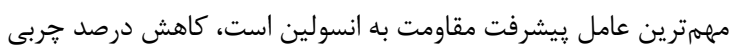

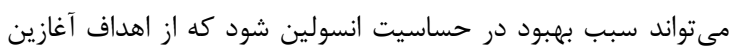

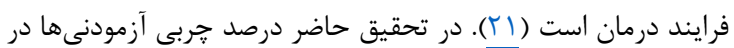

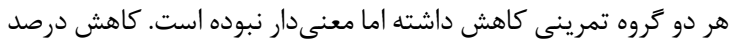

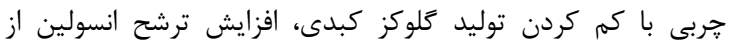

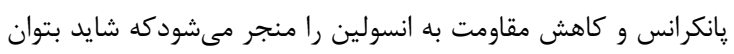

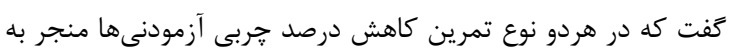

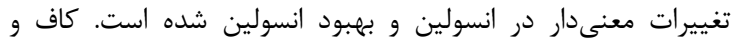

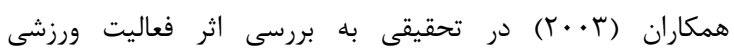

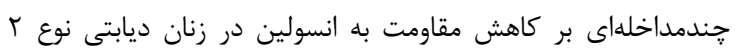

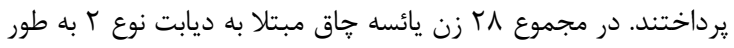

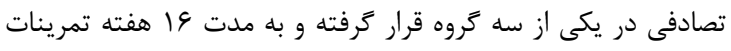

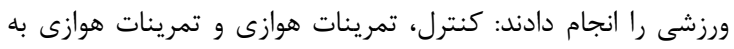

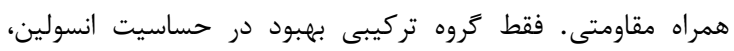

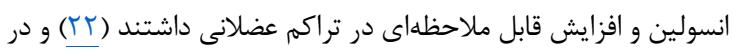

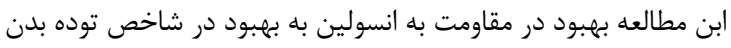

4. Mann S, Beedie C, Jimenez A. Differential effects of aerobic exercise, resistance training and combined exercise modalities on cholesterol and the lipid profile: review, synthesis and recommendations. Sports Med. 2014;44(2):211-21. DOI: $10.1007 / \mathrm{s}$ 40279-013-0110-5 PMID: 24174305

5. Habibi N, Marandi M. [The effect of 12 weeks of yoga on serum levels of glucose,insulin and triglyceride woman with type 2 diabetes]. Diabetes Metab J. 2013.

6. Zamanpour L, Banitalebi E, Amirhosseini SE. The effect of sprint training and combined aerobic and strength training on some inflammatory markers and insulin resistance in women with diabetes mellitus (T2dm). Iranian J Diabetes Metab. 2016;15(5):30011 . 
7. Soriguer F, Garrido-Sanchez L, Garcia-Serrano S, Garcia-Almeida JM, Garcia-Arnes J, Tinahones FJ, et al. Apelin levels are increased in morbidly obese subjects with type 2 diabetes mellitus. Obes Surg. 2009;19(11):1574-80. DOI: 10.1007/s11695-0099955-y PMID: 19756893

8. Besse-Patin A, Montastier E, Vinel C, Castan-Laurell I, Louche K, Dray C, et al. Effect of endurance training on skeletal muscle myokine expression in obese men: identification of apelin as a novel myokine. Int J Obes (Lond). 2014;38(5):707-13. DOI: 10.1038/ijo.2013.158 PMID: 23979219

9. Kadoglou NP, Vrabas IS, Kapelouzou A, Lampropoulos S, Sailer N, Kostakis A, et al. The impact of aerobic exercise training on novel adipokines, apelin and ghrelin, in patients with type 2 diabetes. Med Sci Monit. 2012;18(5):CR290-5. PMID: 22534708

10. Revdal A. Low-volume interval training improves cardiovascular risk factors in type 2 diabetes: A randomized controlled trial: Norges teknisknaturvitenskapelige universitet, Det medisinske fakultet, Institutt for sirkulasjon og bildediagnostikk; 2014.

11. Mannarino M, Tonelli M, Allan GM. Tools for practice: screening and diagnosis of type 2 diabetes with HbA1c. Can Fam Physician. 2013;59(1):42. PMID: 23341657

12. Larose J, Sigal RJ, Khandwala F, Kenny GP. Comparison of strength development with resistance training and combined exercise training in type 2 diabetes. Scand J Med Sci Sports. 2012;22(4):e45-54. DOI: $10.1111 / \mathrm{j} .1600-0838.2011 .01412 . \mathrm{x}$ PMID: 22092541

13. Davis JN, Tung A, Chak SS, Ventura EE, ByrdWilliams CE, Alexander KE, et al. Aerobic and strength training reduces adiposity in overweight Latina adolescents. Med Sci Sports Exerc. 2009;41(7):1494-503. DOI: 10.1249/MSS.0b013e318 19b6aea PMID: 19516150

14. Karavirta L, Hakkinen K, Kauhanen A, ArijaBlazquez A, Sillanpaa E, Rinkinen N, et al. Individual responses to combined endurance and strength training in older adults. Med Sci Sports Exerc. 2011;43(3):484-90. DOI: 10.1249/MSS.0b013e318 1f1bf0d PMID: 20689460

15. Gibala MJ, Little JP, van Essen M, Wilkin GP, Burgomaster KA, Safdar A, et al. Short-term sprint interval versus traditional endurance training: similar initial adaptations in human skeletal muscle and exercise performance. J Physiol. 2006;575(Pt 3):90111. DOI: 10.1113/iphysiol.2006.112094 PMID: 1682 $\underline{5308}$

16. Hovanloo F, Arefirad T, Ahmadizad S. Effects of sprint interval and continuous endurance training on serum levels of inflammatory biomarkers. J Diabetes Metab Disord. 2013;12(1):22. DOI: 10.1186/22516581-12-22 PMID: 23725447

17. Roubenoff R, Hughes VA. Sarcopenia: current concepts. J Gerontol A Biol Sci Med Sci. 2000;55(12):M716-24. PMID: 11129393

18. Higuchi K, Masaki T, Gotoh K, Chiba S, Katsuragi I, Tanaka K, et al. Apelin, an APJ receptor ligand, regulates body adiposity and favors the messenger ribonucleic acid expression of uncoupling proteins in mice. Endocrinology. 2007;148(6):2690-7. DOI: 10. 1210/en.2006-1270 PMID: 17347313

19. Sheibani S, Hanachi P, Refahiat MA. Effect of Aerobic Exercise on Serum Concentration of Apelin, TNFalpha and Insulin in Obese Women. Iran J Basic Med Sci. 2012;15(6):1196-201. PMID: 23653851

20. Choi K, Kim YB. Molecular mechanism of insulin resistance in obesity and type 2 diabetes. Korean $\mathbf{J}$ Intern Med. 2010;25(2):119-29. DOI: 10.3904/kjim. 2010.25.2.119 PMID: 20526383

21. Colberg SR, Sigal RJ, Fernhall B, Regensteiner JG, Blissmer BJ, Rubin RR, et al. Exercise and type 2 diabetes: the American College of Sports Medicine and the American Diabetes Association: joint position statement. Diabetes Care. 2010;33(12):e147-67. DOI: 10.2337/dc10-9990 PMID: 21115758

22. Perri MG, Anton SD, Durning PE, Ketterson TU, Sydeman SJ, Berlant NE, et al. Adherence to exercise prescriptions: effects of prescribing moderate versus higher levels of intensity and frequency. Health Psychol. 2002;21(5):452-8. PMID: 12211512 